\title{
Regulation of the Ubiquitin Proteasome System in Mechanically Injured Human Skeletal Muscle
}

\author{
M. SEIFFERT ${ }^{1}$, D. GOSENCA ${ }^{1}$, N. PONELIES ${ }^{1}$, N. ISING ${ }^{1}$, M. B. PATEL ${ }^{2}$, \\ U. OBERTACKE ${ }^{1}$, M. MAJETSCHAK ${ }^{2}$ \\ ${ }^{1}$ Department for Trauma Surgery, University Hospital Mannheim, Ruprecht-Karls University, \\ Heidelberg, Germany and ${ }^{2}$ Divisions of Trauma and Surgical Critical Care, DeWitt Daughtry \\ Family Department of Surgery, University of Miami, Miller School of Medicine, Miami, FL, USA
}

Received February 14, 2006

Accepted March 23, 2006

On-line available March 23, 2006

\begin{abstract}
Summary
Metabolic consequences of direct muscle trauma are insufficiently defined. Their effects on the ubiquitin-proteasome pathway (UPP) of protein degradation in human skeletal muscles are as yet unknown. Thus, we investigated whether the UPP is involved in the metabolic response evoked in directly traumatized human skeletal muscles. Biopsies were obtained from contused muscles after fractures and from normal muscles during elective implant removal (control). As estimated by western blot analyses, concentrations of free ubiquitin and ubiquitin protein conjugates were similar in extracts from injured and uninjured muscles. Ubiquitin protein ligation rates were reduced after injury (1.5 $\pm 0.2 v s$. $1.0 \pm 0.15 \mathrm{fkat} / \mu \mathrm{g} ; \mathrm{p}=0.04$ ). Chymotryptic-, tryptic- and caspase-like proteasome peptidase activities (total activity minus activity in the presence of proteasome inhibitors) increased significantly after trauma ( $\mathrm{p}=0.04-0.001)$. Significant increases in total chymotryptic- and caspase-like activities were attributable to proteasome activation. Our results extend the possible role of the UPP in muscle wasting to direct muscle trauma. They further suggest that the effects of direct mechanical trauma are not limited to the proteasome and imply that ubiquitin protein ligase systems are also involved. Based on the potential role of the UPP in systemic diseases, it might also be a therapeutic target to influence muscle loss in critically ill blunt trauma patients, in which large proportions of muscle are exposed to direct trauma.
\end{abstract}

\section{Key words}

Catabolism • Muscle cachexia • Ubiquitin-protein ligase complexes • Epoxomicin • Adamantane-acetyl-(6aminohexanoyl) ${ }_{3}$-(leucinyl) $)_{3}$-vinyl-(methyl)-sulfone

\section{Introduction}

Muscle protein wasting is a prominent feature of the metabolic response to a variety of catabolic disease states, such as sepsis, severe trauma, burns, cancer or chronic kidney disease, and its important clinical consequences have been widely recognized (Hasselgren and Fisher 2001, Du and Mitch 2005, Pereira et al. 2005, Wing 2005). Besides systemic activation of muscle protein wasting through a variety of circulating mediators in most of the diseases, the pathophysiology of severe blunt trauma is complicated by the fact that large 
proportions of skeletal muscle are also exposed to direct mechanical trauma.

The molecular mechanisms leading to increased muscle protein degradation have been studied mostly in systemic disease processes. Studies in rodents and patients suggested that stimulation of the ATP-dependent ubiquitin proteasome pathway (UPP) of protein degradation contributes significantly to skeletal muscle wasting (Mitch and Goldberg 1996, Mansoor et al. 1996, Tiao et al. 1997, Hasselgren and Fisher 2001, Du and Mitch 2005, Wing 2005). In the UPP, ubiquitin (Ub) protein ligase systems, which traditionally consist of a $\mathrm{Ub}$ activating enzyme (E1), a Ub carrier or conjugating enzyme (E2) and a Ub protein ligase (E3), catalyze the covalent ligation of $\mathrm{Ub}$ to intracellular proteins in an ATP-dependent process (ubiquitination or ubiquitylation). The ubiquitylated protein is then destined for degradation by the multicatalytic $\mathrm{Mg}^{2+} / \mathrm{ATP}$-dependent $26 \mathrm{~S}$ proteasome, which consists of the $20 \mathrm{~S}$ proteasome, comprising the proteolytic core, and capped by two 19S regulators, which confer $\mathrm{Mg}^{2+} /$ ATP-dependency and ubiquitylated substrate specificity (Hershko and Ciechanover 1998, Wolff and Hilt 2004).

The consequences of direct muscle damage are less well defined and its effects on the UPP in human skeletal muscle are unknown. Therefore, we investigated whether the UPP is affected by direct mechanical trauma in skeletal muscles from patients. For its characterization, we analyzed free $\mathrm{Ub}$ and $\mathrm{Ub}$ protein conjugates, total cytosolic Ub protein ligation rates (Majetschak et al. 2000) and the three main proteasome peptidase activities in skeletal muscle extracts. Since differentiation between systemic and local effects on the UPP is confounded by the systemic inflammatory response to trauma in severely injured patients, we used muscle biopsies from patients with isolated fractures undergoing primary operative repair as a clinical model of direct mechanical trauma.

\section{Methods}

The protocol used was approved by the Ethics Committee of the Faculty of Clinical Medicine Mannheim. Informed consent was obtained from each patient. The study population consisted of 29 patients in the Department of Trauma Surgery (Table 1). Patients fulfilled the following criteria: age $>18$ years, no malignant or infectious disease, rheumatoid arthritis, immunosuppressive medication and known liver, kidney or pancreas disease requiring treatment. Fifteen muscle biopsies were obtained from 14 patients who underwent primary operative fracture repair within $8 \mathrm{~h}$ after trauma. Biopsies (approximately $100 \mathrm{mg}$ ) were obtained during the operation from macroscopically contused muscle adjacent to the fracture. As controls, 16 biopsies from macroscopically normal muscle were obtained from 15 patients who underwent elective implant removal. Biopsies were snap-frozen in liquid nitrogen and stored at $-80{ }^{\circ} \mathrm{C}$ until further analysis. Muscle extracts were prepared using a total protein extraction kit (BioChain, Hayward, CA) according to the manufacturer's instructions and protein concentrations were determined (Lowry et al. 1951). Immunoblotting to $\mathrm{Ub}$ with rabbit anti-Ub (1:500 v/v, Sigma, St. Louis, MO) and densitometric quantification of the chemiluminescence signal were performed as described previously in detail (Majetschak et al. 2003, Ponelies et al. 2005).

The total ubiquitylation rate of cytosolic proteins, as a result of the total Ub-protein ligase activity, was measured as incorporation of biotinylated $\mathrm{Ub}$ into the sum of cytosolic proteins (Majetschak et al. 2000, Ponelies et al. 2005). The ubiquitylation rate is given in katal (1 mol biotinylated Ub incorporated into cytosolic proteins per $\mathrm{s})$. Peptidase activities were measured employing fluorogenic peptide substrates $N$-Suc-LLVY7-amino-4-methylcoumarin (AMC) (chymotryptic-like, $100 \mu \mathrm{M}$ ), Z-AAR-AMC (tryptic-like, $200 \mu \mathrm{M}$ ) or Z-LLE7-AMC (caspase-like $100 \mu \mathrm{M}$ ) (all from Merck, Schwalbach, Germany). Reaction mixtures contained $1 \mathrm{mM}$ DTT, $5 \mathrm{mM}$ ATP, $5 \mathrm{mM} \mathrm{MgCl}_{2}, 50 \mathrm{mM}$ TrisHCl, $\mathrm{pH} 8.0$, peptide substrate and $0.5 \mathrm{mg} / \mathrm{ml}$ freshly prepared muscle extract and were incubated for $60 \mathrm{~min}$ at $37{ }^{\circ} \mathrm{C}$. Free AMC cleaved from the substrates was measured in $15 \mathrm{~min}$ intervals on a fluorescence reader ( $\lambda$ excitation/ emission $=360 / 465 \mathrm{~nm}$, Genios, Tecan, Crailsheim, Germany) against standard curves of AMC (Sigma). To differentiate the proteasome from other peptidase activities, the proteasome inhibitors epoxomicin (1 $\mu \mathrm{M}$; Meng et al. 1999) or adamantane-acetyl-(6-aminohexanoyl) $)_{3}$ (leucinyl) ${ }_{3}$-vinyl-(methyl)-sulfone $(15 \mu \mathrm{M}$, ADA; Kessler et al. 2001) were added to the incubation mixtures for the assessment of chymotryptic-like or tryptic- and caspase-like peptidase activities, respectively. Both proteasome inhibitors were from Biomol (Hamburg, Germany). Proteasome (total peptidase activity minus peptidase activity in the presence of proteasome inhibitor) and proteasome-independent (peptidase activity in the presence of proteasome inhibitor) peptidase activity were determined as mol of AMC cleaved per min. Enzyme time-progression curves showed linearity for all three 
Table 1. Patient characteristics and muscle biopsies

\begin{tabular}{lllll}
\hline Biopsy & Age & Sex & Muscle & Diagnosis \\
\hline Control & & & & \\
1 & 18 & $\mathrm{~F}$ & Gluteus medius & Implant removal \\
2 & 41 & $\mathrm{M}$ & Erector spinae & Implant removal \\
3 & 41 & $\mathrm{M}$ & Extensor carpi radialis & Implant removal \\
4 & 40 & $\mathrm{M}$ & Vastus lateralis & Implant removal \\
5 & 56 & $\mathrm{~F}$ & Deltoideus & Implant removal \\
6 & 54 & $\mathrm{M}$ & Gluteus medius & Implant removal \\
7 & 64 & $\mathrm{~F}$ & Vastus lateralis & Implant removal \\
8 & 28 & $\mathrm{M}$ & Vastus lateralis & Implant removal \\
9 & 35 & $\mathrm{~F}$ & Erector spinae & Implant removal \\
10 & 60 & $\mathrm{~F}$ & Tibialis ant. & Implant removal \\
11 & 64 & $\mathrm{~F}$ & Erector spinae & Implant removal \\
12 & 52 & $\mathrm{~F}$ & Peroneus longus & Implant removal \\
13 & 64 & $\mathrm{~F}$ & Vastus lateralis & Implant removal \\
14 & 54 & $\mathrm{M}$ & Peroneus longus & Implant removal \\
15 & 24 & $\mathrm{M}$ & Gluteus medius & Implant removal \\
16 & 64 & $\mathrm{~F}$ & Erector spinae & Implant removal \\
Total: & $48 \pm 16$ & $9 \mathrm{~F} / 7 \mathrm{M}$ & & \\
\hline
\end{tabular}

\begin{tabular}{lllll}
\hline Injured & & & & \\
1 & 48 & $\mathrm{~F}$ & Deltoideus & \\
2 & 51 & $\mathrm{~F}$ & Triceps humeri & Proximal humerus fracture \\
3 & 79 & $\mathrm{~F}$ & Deltoideus & Supracondylar humerus fracture \\
4 & 50 & $\mathrm{M}$ & Erector spinae & Proximal humerus fracture \\
5 & 58 & $\mathrm{M}$ & Deltoideus & Vertebral fracture (L4) \\
6 & 58 & $\mathrm{M}$ & Biceps brachii & Proximal humerus fracture \\
7 & 29 & $\mathrm{M}$ & Erector spinae & Proximal humerus fracture \\
8 & 41 & $\mathrm{M}$ & Extensor carpi ulnaris & Vertebral fracture (T9) \\
9 & 78 & $\mathrm{~F}$ & Deltoideus & Radius and ulna fracture \\
10 & 85 & $\mathrm{~F}$ & Gluteus medius & Proximal humerus fracture \\
11 & 26 & $\mathrm{~F}$ & Peroneus longus & Proximal femur fracture \\
12 & 32 & $\mathrm{M}$ & Soleus & Proximal tibia fracture \\
13 & 78 & $\mathrm{~F}$ & Deltoideus & Proximal tibia fracture \\
14 & 85 & $\mathrm{~F}$ & Gluteus medius & Proximal humerus fracture \\
15 & 76 & $\mathrm{~F}$ & Extensor digitorum & Proximal femur fracture \\
Total: & $58 \pm 22$ & $9 \mathrm{~F} / 6 \mathrm{M}$ & & Distal radius fracture \\
\hline
\end{tabular}

Data are mean \pm SD. F: Female. M: Male. Biopsies 2 and 3 (control) and biopsies 5 and 6 (injured) were obtained from the same patient. Age and gender distribution were similar in both groups $\left(p>0.05\right.$, $t$-test and $\chi^{2}$-test, respectively).

peptidase activities. The data are described as the mean \pm SD. Statistics were calculated with the SPSS for Windows Release 13.0 program (t-test, chi-square test $\left(\chi^{2}\right)$ ). A two-tailed $\mathrm{p}<0.05$ was considered as significant.

\section{Results and Discussion}

Representative immunoblotting experiments are shown in Fig. 1A and revealed no visible differences between 
control and injured muscles. Densitometric quantification confirmed that the concentrations of total $\mathrm{Ub}$ (control $(\mathrm{n}=10)$ : $13 \pm 1 \mathrm{ng} / \mu \mathrm{g}$ protein; injured ( $\mathrm{n}=11): 13.3 \pm 1 \mathrm{ng} / \mu \mathrm{g}$ protein), free $\mathrm{Ub}$ (control $(\mathrm{n}=10): 1.5 \pm 0.06 \mathrm{ng} / \mu \mathrm{g}$ protein; injured $(\mathrm{n}=11): 1.6 \pm 0.1 \mathrm{ng} / \mu \mathrm{g}$ protein) and $\mathrm{Ub}$ protein conjugates (control ( $\mathrm{n}=10): 11.5 \pm 1 \mathrm{ng} / \mu \mathrm{g}$ protein; injured $(\mathrm{n}=11): 11.7 \pm 1$ $\mathrm{ng} / \mu \mathrm{g}$ protein) were similar ( $\mathrm{p}>0.05$ for all comparisons).

Figure 1B shows the initial progress curves of Ub protein ligation. We observed a lag-phase of about 2.5 min with a subsequent linear increase in ubiquitylation. Based on the initial progress curves, $\mathrm{Ub}$ protein ligation rates were $1.5 \pm 0.2 \mathrm{fkat} / \mu \mathrm{g}$ in the controls $(\mathrm{n}=11)$ and $1.0 \pm 0.15 \mathrm{fkat} / \mathrm{\mu g}$ in injured muscles $(\mathrm{n}=12)$, which was significantly lower (Fig. 1C, $p=0.04$ ). We have shown recently that $\mathrm{Ub}$ protein ligation is also significantly reduced in human mononuclear cells after endotoxin stimulation in vitro and in mononuclear cells from patients with sepsis (Majetschak et al. 2000, Ponelies et al. 2005). Although the clinical relevance of reduced ubiquitylation rates and the underlying mechanism remain to be determined, we interpret its significant reduction in injured muscle as a common cell response to infectious and non-infectious inflammation in general, that could be aimed to prevent uncontrolled proteolysis.

Total peptidase activities were higher in injured $(n=5)$ than in control $(n=5)$ muscles (tryptic-like: $2.9 \pm 0.8$ and $1.7 \pm 0.5 \mathrm{pmol} / \mathrm{min} \quad(\mathrm{p}=0.4)$, chymotryptic-like: $1.5 \pm 0.2$ and $0.6 \pm 0.07 \mathrm{pmol} / \mathrm{min}(\mathrm{p}=0.006)$, caspase-like: $0.4 \pm 0.05$ and $0.1 \pm 0.01 \mathrm{pmol} / \mathrm{min}(\mathrm{p}<0.001)$ for injured and control, respectively). This finding is consistent with previous data from rodents, which showed a marked decrease in total protein content and an increase in overall proteolytic rates in skeletal muscle after direct mechanical trauma (Fisher et al. 1990, Farges et al. 2002). Addition of proteasome inhibitors reduced trypticlike peptidase activities by $17 \pm 5 \%$ (control) and $21 \pm 4 \%$ (injured), chymotryptic-like activities by $79 \pm 3 \%$ (control) and $78 \pm 2 \%$ (injured), and caspase-like activities by $94 \pm 5 \%$ (control) and $95 \pm 1 \%$ (injured) without significant differences between control and injured muscle. The proteasome peptidase activities (Fig. 1D-F, grey bars) were significantly higher for all three substrates in injured muscles. In contrast, we did not observe significant differences between control and injured muscles for the proteasome-independent trypticand caspase-like activities (Fig. 1D-F, open bars). Thus, the results suggest that increased total chymotryptic- and caspase-like peptidase activities can be attributed predominantly to proteasome activation.

Our finding of proteasome activation contradicts a recent study which reported unchanged proteasome activity at $48 \mathrm{~h}$ after direct mechanical injury, assessed as MG132-dependent tyrosin release from dissected gastrocnemius strips (Farges et al. 2002). The different experimental procedures that were used to assess proteasome contribution could possibly explain these controversial findings. The peptide aldehyde MG132 is a reversible inhibitor of the chymotryptic-like site. Epoxomicin and ADA are irreversible inhibitors. While epoxomicin, which is one of the most selective proteasome inhibitors, predominantly inhibits chymotryptic-like proteasome activity, ADA has comparable affinity for all catalytic subunits (Meng et al. 1999, Kessler et al. 2001, Kisselev and Goldberg 2001). Both methods, i.e. measuring tyrosin release from dissected muscle strips and measurement of peptidase activities in cell free extracts, have major limitations and provide only indirect assessment of proteasome activity in vitro (Kisselev and Goldberg 2001, Rodgers and Dean 2003, Kukan 2004). Furthermore, proteasome activity was assessed at a time point when total proteolytic rates peaked in the experimental model (Farges et al. 2002), while muscle biopsies were collected at an earlier time point in patients. Although the time course of proteolytic activation in injured human muscle is unknown, the kinetics of proteasome activation after injury may not necessarily resemble kinetics of total or non-proteasomal proteolytic activation in rodents or humans. This hypothesis is supported by peptidase activity measurements in muscle extracts from a patient (Table 1, \#11) who underwent a second-look operation at $72 \mathrm{~h}$ after injury and during which we could obtain a second biopsy. Comparison of peptidase activities within $8 \mathrm{~h}$ and at $72 \mathrm{~h}$ after trauma showed that all three proteasome activities increased 1.5 to 4 -fold by $72 \mathrm{~h}$ (pmol/min: tryptic-like $0.2(<8 \mathrm{~h})$ and $0.76(72 \mathrm{~h})$; chymotryptic-like -0.89 $(<8 \mathrm{~h})$ and $1.38(72 \mathrm{~h})$; caspase-like $-0.22(<8 \mathrm{~h})$ and $0.55(72 \mathrm{~h})$ ). Proteasome independent tryptic-like activity increased 10-fold, chymotryptic-like activity 1.2-fold, whereas proteasome independent caspase-like activity decreased 2-fold (pmol/min: tryptic-like $-0.4(<8 \mathrm{~h})$ and $4.0(72 \mathrm{~h})$; chymotryptic-like $-0.28(<8 \mathrm{~h})$ and 0.33 $(72 \mathrm{~h})$; caspase-like $-0.02(<8 \mathrm{~h})$ and $0.01(72 \mathrm{~h}))$. Another possible explanation is that the severity of mechanical injury in rats might have been below the biological threshold of proteasome activation. Since we detected a significant increase in total peptidase activities 




D

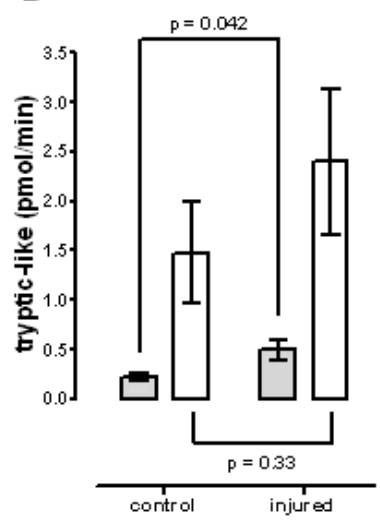

B

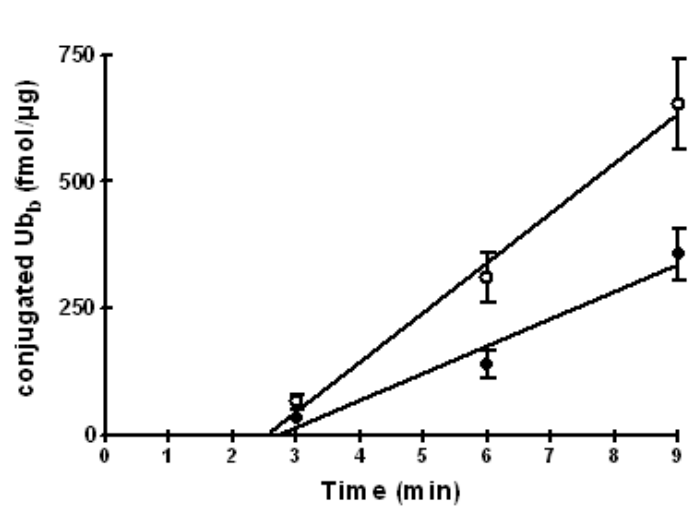

$\mathbf{E}$

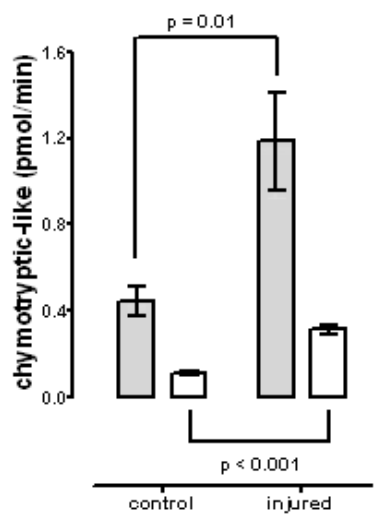

C

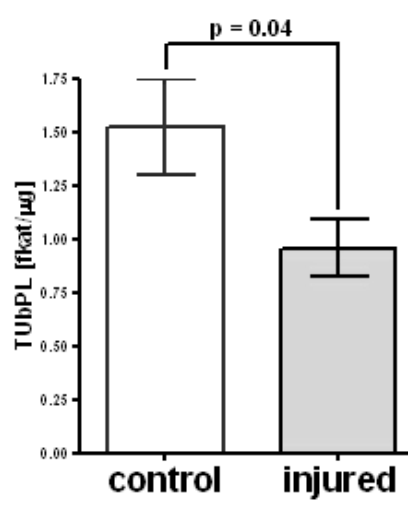

$\mathbf{F}$

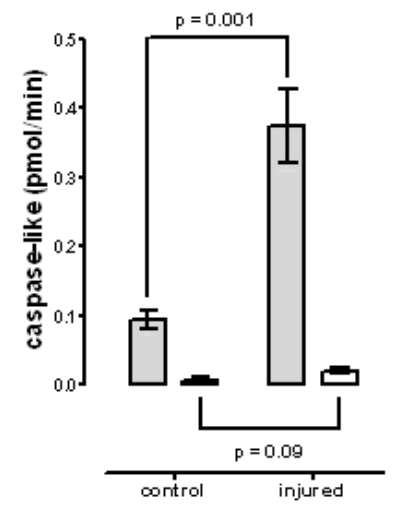

Fig. 1. A. Typical immunoblot for ubiquitin in control and injured muscle extracts. Ub: Ubiquitin. Left: Position of the molecular mass standards. C: Control muscle. I: Injured muscle. GM: Gluteus medius muscle. ES: Erector spinae muscle. D: Deltoid muscle. Lanes 1 6: Each lane contains $30 \mu \mathrm{g}$ of muscle extract protein. Lanes 1 and 2: GM, control and injured. Lanes 3 and 4: ES, control and injured. Lanes 5 and 6: D, control and injured. Lanes 7-9: Ub standards, 100, 50 and $10 \mathrm{ng}$, respectively. B. Initial progress curves of ubiquitin protein ligation in muscle extracts. $U_{b}$ : Biotinylated ubiquitin. Data are mean \pm SD. Open circles: Control $(n=11)$. Filled circles: Injured $(n=12)$. Line: Linear regression curves $\left(r^{2}=0.96-0.98\right)$. C. Total ubiquitin protein ligation rates (TUbPL) in muscle extracts. Data are mean \pm SD. Open bars: Control $(n=11)$. Grey bar: Injured $(n=12)$. D.-F. Peptidase activities in muscle extracts. Data are mean \pm S.D. Open bars: Proteasome independent peptidase activity $(n=5)$. Grey bars: Proteasome peptidase activity $(n=5)$. D. Tryptic-like peptidase activity. E. Chymotryptic-like peptidase activity. F. Caspase-like peptidase activity.

at a time point when total proteolysis was not significantly increased in the animal model $(<8 \mathrm{~h}$ after trauma), the mechanical impact in our study appears to be higher and could possibly not have been high enough to affect the ubiquitin proteasome system in the experimental model.

It is certainly a limitation of the present study that we were unable to quantify and compare the mechanical impact with experimental data in rats. However, all injured muscle biopsies were obtained from areas adjacent to the fracture indicating a biologically relevant soft tissue trauma. Another limitation is that extracts were prepared without addition of protease or $\mathrm{Ub}$ hydrolase inhibitors. Thus, quantification of the cellular $\mathrm{Ub}$ pool and $\mathrm{Ub}$ protein ligation rates could have been affected by increased proteolysis or altered Ub hydrolase activities in the extracts. However, we did not detect alterations of the cellular $\mathrm{Ub}$ pool after direct mechanical trauma, as would have been expected if altered protein degradation or hydrolysis of Ub-protein conjugates had occured in vitro. In addition, our preliminary data show that activation of proteasome peptidase activity in skeletal muscle is not directly reflected by alterations of the cellular $\mathrm{Ub}$ pool in animals after traumatic shock and hemorrhage (Patel and Majetschak, unpublished observation). Therefore, it cannot be ruled out that changes would have been detectable at other time points.

In conclusion, the present study supports previous findings that increased proteolytic rates are a determinant of protein loss in direct muscle trauma 
(Farges et al. 2002). In line with studies on systemic catabolic disease states, our results further support the hypothesis that the UPP is critical during muscle wasting and extend its role to direct muscle trauma. Furthermore, they suggest that the effects of mechanical trauma are not limited to the proteasome and imply that $\mathrm{Ub}$ protein ligase systems are also affected. Therefore, the UPP might be a target to influence muscle loss in critically ill blunt trauma patients, e.g. by the therapeutic use of proteasome inhibitors.

\section{Acknowledgements}

We thank Anja Bistron for excellent technical help. This research was supported by a grant from the Deutsche Forschungsgemeinschaft (DFG MA 2474/2-1 and 2-2 to M.M.).

\section{References}

DU J, MITCH WE: Identification of pathways controlling muscle protein metabolism in uremia and other catabolic conditions. Curr Opin Nephrol Hypertens 14: 378-382, 2005.

FARGES MC, BALCERZAK D, FISHER BD, ATTAIX D, BECHET D, FERRARA M, BARACOS VE: Increased muscle proteolysis after local trauma mainly reflects macrophage-associated lysosomal proteolysis. Am J Physiol 282: E326-E335, 2002.

FISHER BD, BARACOS VE, SHNITKA TK, MENDRYK SW, REID DC: Ultrastructural events following acute muscle trauma. Med Sci Sports Exerc 22: 185-193, 1990.

HASSELGREN PO, FISCHER JE: Muscle cachexia: current concepts of intracellular mechanisms and molecular regulation. Ann Surg 233: 9-17, 2001.

HERSHKO A, CIECHANOVER A. The ubiquitin system. Annu Rev Biochem 67:425-479, 1998.

KESSLER BM, TORTORELLA D, ALTUN M, KISSELEV AF, FIEBIGER E, HEKKING BG, PLOEGH HL, OVERKLEEFT HS: Extended peptide-based inhibitors efficiently target the proteasome and reveal overlapping specificities of the catalytic beta-subunits. Chem Biol 8: 913-929, 2001.

KISSELEV AF, GOLDBERG AL: Proteasome inhibitors: from research tools to drug candidates. Chem Biol 8: 739$758,2001$.

KUKAN M: Emerging roles of proteasomes in ischemia-reperfusion injury of organs. J Physiol Pharmacol 55: 3-15, 2004.

LOWRY OH, ROSEBROUGH NJ, FARR AL, RANDALL RJ: Protein measurement with the Folin phenol reagent. J Biol Chem 193: 265-75, 1951.

MAJETSCHAK M, SUCIU DM, HASLER K, OBERTACKE U, SCHADE FU, JENNISSEN HP: Cytosolic protein ubiquitylation in normal and endotoxin stimulated human peripheral blood mononuclear cells. J Endotoxin Res 6: 483-488, 2000.

MAJETSCHAK M, KREHMEIER U, BARDENHEUER M, DENZ C, QUINTEL M, VOGGENREITER G, OBERTACKE U: Extracellular ubiquitin inhibits the TNF $\alpha$ response to endotoxin in peripheral blood mononuclear cells and regulates endotoxin hyporesponsiveness in critical illness. Blood 101: 1882-1890, 2003.

MANSOOR O, BEAUFRERE B, BOIRIE Y, RALLIERE C, TAILLANDIER D, AUROUSSEAU E, SCHOEFFLER P, ARNAL M, ATTAIX D: Increased mRNA levels for components of the lysosomal, $\mathrm{Ca}^{2+}$-activated, and ATP-ubiquitin-dependent proteolytic pathways in skeletal muscle from head trauma patients. Proc Natl Acad Sci USA 93: 2714-2718, 1996.

MENG L, MOHAN R, KWOK BH, ELOFSSON M, SIN N, CREWS CM: Epoxomicin, a potent and selective proteasome inhibitor, exhibits in vivo antiinflammatory activity. Proc Natl Acad Sci USA 96: 10403-10408, 1999.

MITCH WE, GOLDBERG AL: Mechanisms of muscle wasting: the role of the ubiquitin-proteasome pathway. New Engl J Med 335: 1897-1905, 1996.

PEREIRA C, MURPHY K, JESCHKE M, HERNDON DN: Post burn muscle wasting and the effects of treatments. Int J Biochem Cell Biol 37: 1948-1961, 2005.

PONELIES N, KREHMEIER U, HIRSCH T, DENZ C, PATEL MB, MAJETSCHAK M: Cytosolic ubiquitin levels and ubiquitylation rates in human peripheral blood mononuclear cells during sepsis. Shock 24: 20-25, 2005. 
RODGERS KJ, DEAN RT: Assessment of proteasome activity in cell lysates and tissue homogenates using peptide substrates. Int J Biochem Cell Biol 35: 716-727, 2003.

TIAO G, HOBLER S, WANG JJ, MEYER TA, LUCHETTE FA, FISCHER JE, HASSELGREN PO: Sepsis is associated with increased mRNAs of the ubiquitin-proteasome proteolytic pathway in human skeletal muscle. J Clin Invest 99: 163-168, 1997.

WING SS: Control of ubiquitination in skeletal muscle wasting. Int J Biochem Cell Biol 37: 2075-2087, 2005.

WOLF DH, HILT W: The proteasome: a proteolytic nanomachine of cell regulation and waste disposal. Biochem Biophys Acta 1695: 19-31, 2004.

\section{Corresponding author}

M. Majetschak, DeWitt Daughtry Family Department of Surgery, Divisions of Trauma and Surgical Critical Care, University of Miami Miller School of Medicine, 1800 NW 10th Ave., Miami, FL 33136, USA. Fax: ++1 3052437354.

E-mail: mmajetschak@med.miami.edu 